\title{
Kemampuan Guru Menggunakan TIK Untuk Pengembangan di Taman Kanak-Kanak
}

\author{
Febrialismanto ${ }^{1}$, Hidayatun $\mathrm{Nur}^{2}$ \\ 1Prodi PG PAUD FKIP Universitas Riau, \\ 2Prodi Bahasa Indonesia FKIP Universitas Islam Riau \\ email:1febrialismanto@lecturer.unri.ac.id,2hidayatunnur87@gmail.com
}

\begin{abstract}
.
The progress of the era is recognised by the development of Technology and Information. Almost everyone uses technology and information in their lives. The use of Technology and Information has entered the world of education. The teacher has a big role to use technology and information in learning. The purpose of this study was to determine the ability of teachers to use ICTs for development in kindergartens, Riau Province. In kindergarten there is a development that should get attention in learning that is cognitive, language, physical, social \& emotional, religious \& moral values, and art. From the research results, it can be seen that teachers use Technology and Information for development is still low. Besides that the use of ICTs makes teaching materials, change learning, store materials and learning outcomes, communicate learning materials and results, and disseminate information on materials and learning outcomes of teachers are categorized into the low category.
\end{abstract}

Keywords: ICT, Development, Advancement, Early Childhood Education Teachers

\begin{abstract}
ABSTRAK.
Kemajuan zaman ditandai dari berkembangnya kemajuan dalam Teknologi dan Informasi. Hampir semua orang menggunakan Teknologi dan informasi dalam semua pada saat ini dalam kehidupannya. Penggunaan Teknologi dan Informasi sudah masuk dalam dunia pendidikan. Guru memiliki peran yang besar memanfaatkan teknologi dan informasi dalam pembelajaran. Tujuan penelitian ini untuk mengetahui kemampauan guru menggunakan TIK untuk pengembangan di Taman Kanak-Kanak di Provinsi Riau. Di Taman Kanak-kanak ada pengembangan yang harus mendapatkan perhatian dalam pembelajaran yaitu kognitif, bahasa, fisik motorik, sosial \& emosional, nilai agama \& moral, dan seni. Dari hasil penelitian dapat diketahui guru menggunakan Teknologi dan Informasi untuk pengembangan masih rendah. Disamping itu Penggunaan TIK membuat bahan ajar, mengubah pembelajaran, menyimpan bahan dan hasil pembelajaran, mengkomunikasikan bahan dan hasil pembelajaran, serta menyebarkan informasi bahan dan hasil pembelajaran guru termasuk dalam kategori rendah.
\end{abstract}

Kata Kunci: TIK, Perkembangan, Pengembangan, Guru PAUD 


\section{Febrialismanto1, Hidayatun Nur2}

\section{PENDAHULUAN}

Penguasaan teknologi dalam pembelajaran sudah menjadi keharusan bagi seorang guru. Guru saat ini harus dapat mengoperasikan teknologi yang dapat digunakan sekagai alat informasi ataupun komunikasi. Kemampuan penggunaan teknologi inforasi dan komunikasi menjadikan guru lebih cepat memberikan dan mendapatkan informasi. Kemampuan mendapatkan dan memberikan informasi merupakan modal guru untuk melakukan pembelajaran. Dalam proses pembelajaran keterbaharuan pengetahuan yang diberikan kepada peserta didik sangat diperlukan hal ini dikarenakan supaya anak didik mendapatkan pengetahuan yang baru supaya nantinya dapat menjadi persiapan peserta didik mempersiapkan diri untuk menghadapai tantangan pada masa yang akan datang. Memperkenalkan teknologi kepada peserta didik diperlukan kemahiran atau keahlian guru terlebih dahulu dalam penguasaan teknologi. Guru yang memiliki kemampuan yang baik dalam bidang teknologi akan lebih terbantu dalam proses pembelajaran dengan menggunakan teknologi jika dibandingkan guru yang belum terlalu mahir atau sama sekali belum dapat menguasai teknologi dalam pembelajaran. Mempersiapkan diri merupakan modal dasar guru dalam menghadapi tantangan pembelarang dalam bidang teknologi.

Pada pembelajaran pengembangan perkembangan di Taman Kanak-kanak ada beberapa aspek perkembangan yang harus mendapatkan perhatian guru seperti penjelasan (Indonesia, 2014) yaitu nilai agama dan moral, fisik motorik, kognitif, bahasa, sosial emosional, dan seni. Perkembangan anak tersebut dalam proses pembelajaran harus mendapatkan pengembangan dalam pembelajaran. (Rahman, 2009) pada anak usia dini proses pendidikan yang diawali dari lahir sampai usia 6 tahun memiliki karakteristik pengembangan yang harus mendapatkan perhatian berupa motorik, kognitif, sosial-emosional dan bahasa. Karakteristik anak usia dini yang harus mendapatkan perhatian tersebut diharapkan berkembang dengan baik. Proses pengembanganya dimulai dari orang tua di rumah dan guru di sekolah. Peran guru di sekolah menjadi faktor penentunya aspek perkembangan anak dapat berkembang dengan baik. Peran yang dilakukan guru tidak terlepas dari kemampuan yang dimiliki oleh guru tersebut dalam proses pembelajaran.

Pada saat ini pengembangan banyak dilakukan hanya dengan menggunakan cara yang konvensional. Penggunaan TIK dalam pembelajaran pengembangan masih jarang dijumpai. (Rusi Restiyani, Nengsi Juanengsih, 2013) menjelaskan bahwa kemampuan literasi guru yang berupa kemampuan membaca, berbicara, melihat, mendengarkan dan berpendapat yang baik berpotensi pada kemampuan pemamfaatan TIK. Artinya guru yang mau menigkatkan 
kualitasnya akan memberikan dampak yang baik terhadap pemanfatan terhadap TIK. Pemanfaatan TIK dalam pembelajaran merupakan tantangan bagi guru masa depan.

\section{METODE PENELITIAN}

Metode yang digunakan dalam penelitian ini adalah metode penelitian deskriptif kuantitatif. Metode desktiptif kuantitatif melihat bagaimana kondisi variable penelitian dengan melihat indikator-indikator yang menerangkan variabel tersebut. Sampel penelitian menggunakan metode sampling insidental yakni teknik pengambilan sampel berdasarkan kebetulan bertemu atau berpartisipasi dalam penelitian. Sampel merupakan orang yang dipandang cocok sebagai sumber data. Sampel penelitian ini adalah guru yang berada di Provinsi Riau yang berpartisipasi mengisi angket online. Guru yang berpartisipasi sebanyak 67 orang.

\section{HASIL DAN PEMBAHASAN}

Untuk menentukan kriteria hasil perhitungan deskriftif menggunakan pedoman pengukuan sebagai berikut (Febrialismanto \& Hukmi, 2018):
a. $>80 \% \quad$ : Tinggi
b. $>60 \%-<80 \%$ : Cukup Tinggi
c. $>40 \%-<60 \%$ : Rendah
d. $<40 \% \quad$ : Sangat Rendah

\section{Hasil}

- Menggunakan teknologi membuat bahan pembelajaran Pengembangan Kognitif untuk AUD

- Menggunakan teknologi membuat bahan pembelajaran Pengembangan Bahasa untuk AUD

- Menggunakan teknologi membuat bahan pembelajaran Pengembangan Fisik Motorik untuk AUD

- Menggunakan teknologi membuat bahan pembelajaran Pengembangan Kecerdasan Sosial \& Emosional untuk AUD

- Menggunakan teknologi membuat bahan pembelajaran

Pengembangan Nilai Agama \& Moral untuk AUD

- Menggunakan teknologi membuat bahan pembelajaran

Pengembangan Seni untuk AUD

- Menggunakan teknologi membuat bahan pembelajaran Pengembangan Sains untuk AUD

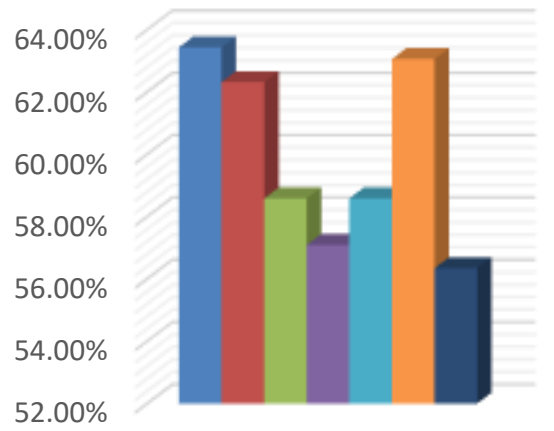

Gambar 1. Menggunakan teknologi membuat bahan pembelajaran Pengembangan 
rata-rata gambar 1. (59.91\% kategori rendah)

- Menggunakan teknologi mengubah pembelajaran Pengembangan Kognitif untuk AUD

- Menggunakan teknologi mengubah pembelajaran Pengembangan Bahasa untuk AUD

- Menggunakan teknologi mengubah pembelajaran Pengembangan Fisik

Motorik untuk AUD

- Menggunakan teknologi mengubah pembelajaran Pengembangan

Kecerdasan Sosial \& Emosional untuk AUD

- Menggunakan teknologi mengubah pembelajaran Pengembangan Nilai

Agama \& Moral untuk AUD

- Menggunakan teknologi mengubah pembelajaran Pengembangan Seni untuk AUD

- Menggunakan teknologi mengubah pembelajaran Pengembangan Sains untuk AUD

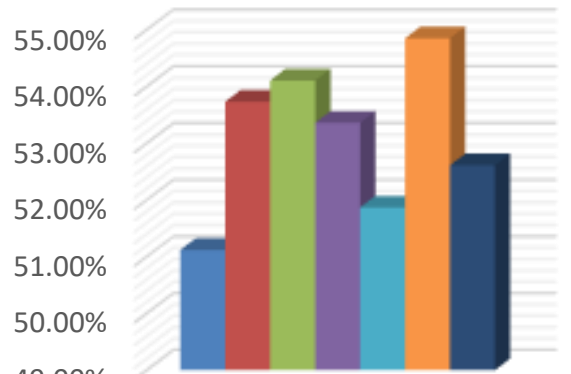

Gambar 2. Menggunakan teknologi mengubah pembelajaran Pengembangan

rata-rata gambar 2. (53.09\% kategori rendah)

Menggunakan Teknologi menyimpan bahan dan hasil pembelajaran

Pengembangan Kognitif untuk AUD

- Menggunakan Teknologi menyimpan bahan dan hasil pembelajaran Pengembangan Bahasa untuk AUD

- Menggunakan Teknologi menyimpan bahan dan hasil pembelajaran Pengembangan Fisik Motorik untuk AUD

- Menggunakan Teknologi menyimpan bahan dan hasil pembelajaran Pengembangan Kecerdasan Sosial \& Emosional untuk AUD

- Menggunakan Teknologi menyimpan bahan dan hasil pembelajaran Pengembangan Nilai Agama \& Moral untuk AUD

- Menggunakan Teknologi menyimpan bahan dan hasil pembelajaran Pengembangan Seni untuk AUD

$60.00 \%$

$59.00 \%$

$58.00 \%$

$57.00 \%$

$56.00 \%$

$55.00 \%$

$54.00 \%$

$53.00 \%$

$52.00 \%$

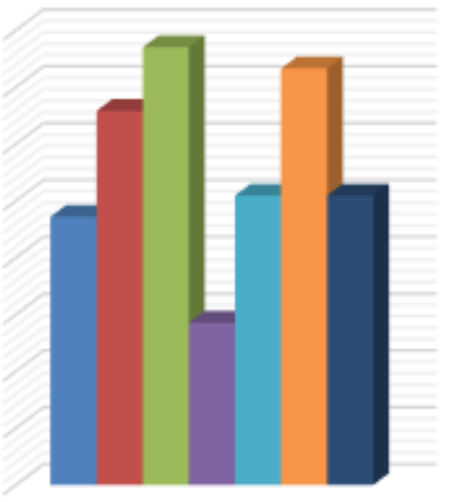

- Menggunakan Teknologi menyimpan bahan dan hasil pembelajaran Pengembangan Sains untuk AUD

\section{rata-rata gambar 3. (57.62\% kategori rendah)}

- Menggunakan teknologi mengkomunikasikan bahan dan hasil pembelajaran Pengembangan Kognitif untuk AUD

- Menggunakan teknologi mengkomunikasikan bahan dan hasil pembelajaran Pengembangan Bahasa untuk AUD

- Menggunakan teknologi mengkomunikasikan bahan dan hasil pembelajaran Pengembangan Fisik Motorik untuk AUD

- Menggunakan teknologi mengkomunikasikan bahan dan hasil pembelajaran Pengembangan Kecerdasan Sosial \& Emosional untuk

- Menggunakan teknologi mengkomunikasikan bahan dan hasil pembelajaran Pengembangan Nilai Agama \& Moral untuk AUD

$58.00 \%$

$57.00 \%$

$56.00 \%$

$55.00 \%$

$54.00 \%$

$53.00 \%$

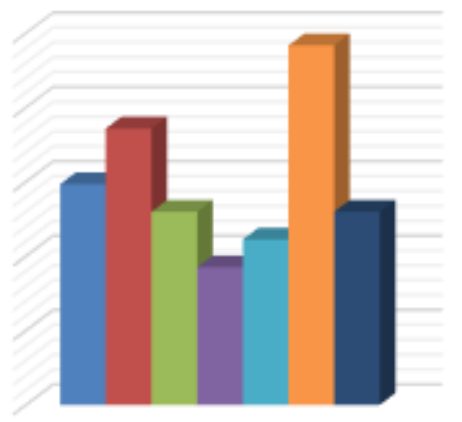

- Menggunakan teknologi mengkomunikasikan bahan dan hasil pembelajaran Pengembangan Seni untuk AUD

- Menggunakan teknologi mengkomunikasikan bahan dan hasil pembelajaran Pengembangan Sains untuk AUD

Gambar 4. Menggunakan teknologi mengkomunikasikan bahan dan hasil pembelajaran Pengembangan 
rata-rata gambar 4. (55.97\% kategori rendah)

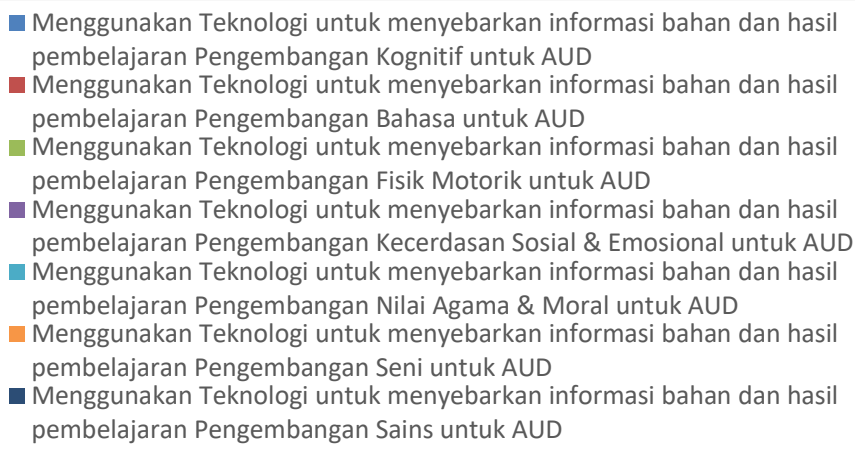

- Menggunakan Teknologi untuk menyebarkan informasi bahan dan hasil pembelajaran Pengembangan Sains untuk AUD

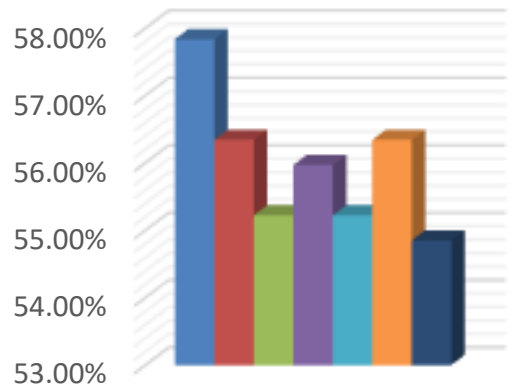

Gambar 5. Menggunakan Teknologi untuk menyebarkan informasi bahan dan hasil pembelajaran Pengembangan

rata-rata gambar 5 (55.97\% kategori rendah)

\section{Pembahasan}

\section{a. Menggunakan teknologi membuat bahan pembelajaran Pengembangan 59.91\% kategori rendah}

Membuat bahan ajar pengembangan merupakan tugas dari setiap guru dalam proses pembelajaran di sekolah. Pada umumnya guru sudah mampu membuat bahan pembelajaran. Kebutuhan saat ini ketika guru diminta untuk membuat bahan pengembangan dengan menggunakan teknologi menjadi tantangan bagi guru untuk menguasai teknologi agar dapat membuat bahan pembelajaran. (Arsanti, 2018) peserta didik mengharapkan dan membutuhkan terhadap pengembangan bahan ajar kreatif. Penguasaan guru terhadap teknologi merupakan modal untuk membuat bahan ajar. Penguasaan yang baik akan membantu guru untuk membuat bahan ajar yang lebik kratif. Kreatifnya seorang guru akan memberikan warna dari bahan ajar sehingga akan memberikan daya tarik dari pembelajaran yang diberikan di kelas. Kondisi ini memberikan nilai tawar guru untuk dapat mengendalikan pembelajaran agar lebih baik lagi. Dengan media yang diminati anak partisipasi anak lebih meningkat dalam proses pembelajaran. (Zakiah, Suyono, \& Roekhan, 2012) guru merupakan orang yang dijadikan tempat bertanya oleh peserta didik dalam pembelajaran, guru merupakan orang yang membantu untuk memberikan jawaban dari pembelajaran yang dilaksanakan oleh karena iitu guru diharapkan sudah mempersiapkan dengan baik sebelum pembelajaran dimulai. (Romansyah, 2016) pemilihan dan penyajian bahan ajar harus sesuai dengan kriteria penulisan yang berlaku umum seperti prinsipprinsip, tahap-tahap pemilihan, prinsip pemilihan, dan kriteria penyajian bahan ajar. (Zuriah, Sunaryo, \& Yusuf, 2016) guru yang mendapatkan pelatihan untuk pengembangan pembelajaran 


\section{Febrialismanto1, Hidayatun Nur2}

akan meningkatkan kompetensi profesional dan kompetensi pedagogik guru. (Wirastuti, Hartawan, Suyadnya, \& Khrisne, 2018) memberikan pelatihan kepada guru untuk menggunakan Teknologi dalam pembealajaran diperlukan karena akan meningkat pengetahuan guru terhadap pengetahuan teknologi tersebut. Memberikan pelatihan kepada guru meningkat partisipasi guru untuk mempelajari teknologi. (Chaidar, 2014) penggunaan teknologi dalam pembelajaran belum digunakan sepenuhnya oleh guru, guru masih berpandangan bahwa penggunaan teknologi dalam pembelajaran baru sebatas penggunaan media power point dalam pembelajaran. Penggunaan internet dan jaring sosial belum digunakan dengan baik. Disamping itu penggunaan teknologi dalam pembelajaran terhambat akibat kurangnya sarana dan prasara pendukung. Diperlukan pelatihan dan dorongan motivasi kepada guru baik dari pihak sekolah dan luar sekolah dalam penggunaan teknologi pembelajaran.

\section{b. Menggunakan teknologi mengubah pembelajaran Pengembangan $53.09 \%$ kategori rendah}

(Budiman, 2017) tuntutan global dalam dunia pendidikan sekarang ini untuk menyesuaikan dengan perkembangan teknologi. Perkembangan tersebut terutama dalam pembelajaran. (Setyosari, 2015) penggunaan teknologi dalam kehidupan tidak dapat dielakkan, penggunaan teknologi juga merambah dalam dunia pendidikan. Memberikan fasilitas untuk penggunaan teknologi akan lebih baik dengan diberikan fasilitas yang baik. Penggunaan teknologi lebih baik dengan meingkatkan kemampuan literasi guru. (Saida Ulfa, 2016) perkembangan teknologi menyatu dalam kehidupan sehari-hari dan digunakan untuk berinteraksi dalam lingkungan hidup. Penggunaan teknologi memberikan dampak untuk mengenal literasi lebih banyak lagi. Pendidik harus memperhatikan penggunaan teknologi agar dapat digunakan untuk perkembangan anak. Dengan teknologi memberikan kemudahan untuk mengenalkan sesuatu yang baru kepada anak. (Juraman, 2014a) memberikan pelatihan kepada guru untuk menggunakan TIK mampu memberikan perubahan cara berpikir guru dalam merancang pembelajaran yang awalnya dari konvensional ke arak interaktif. Guru harus mampu menguasai teknologi agar tidak menjadi guru yang tertinggal. (Yaumi, 2016) teknologi memberikan pengetahuan praktis bagi yang menggunakannya. Teknologi pembelajaran berupa penguasaan dan pemanfaatan yang dapat digunakan dalam proses dan sumber belajar termasuk dalam memfasilitasi belajar. (Ahmadi, 2018) guru harus mendapatkan pengetahuan dan kemampuan untuk menggunakan teknologi, menggunakan teknologi dengan cara yang tepat dapat memberikan manfaat kepada guru dan juga kepada peserta didik. Interaksi dengan menggunakan teknologi yang digunakan oleh guru dan peserta didik akan mengembangkan kemampuan berpikir peserta didik dan pembelajaran lebih 


\section{Febrialismanto1, Hidayatun Nur2}

terpusat pada peserta didik sehingga peserta didik lebih percaya diri dan meningkat motivasinya dalam belajar.

\section{c. Menggunakan Teknologi menyimpan bahan dan hasil pembelajaran Pengembangan $57.62 \%$ kategori rendah}

(Mutia, 2016) penggunaan aplikasi cloud computing dapat mempermudah penggunaan teknologi dalam pembelajaran, salah satu kemudahannya adalah penyimpanan data sehingga yang diperlukan adalah koneksi terhadap komputer. (Rifauddin, 2016) penyimpanan dengan menggunakan media elektronik merupakan penyimpanan yang baru. Nilai dan kegunaan dalam penyimpanan memiliki nilai yang sama dengan penyimpanan manual. Penyimpanan dapat dilakukan pada saat online, offline dan nearline. Penyimpanan dapat dilakukan dengan menggunakan hardisk, CD, dan sebagainya. Untuk media online penyimpanan dapat dilakukan dengan menggunakan internet. Keamanan penyimpanan dengan menggunakan media elektronik lebih terjaga dengan baik. (Cahyono, 2012) salah satu peyimpanan online dapat menggunakan google drive. Penggunaan google drive ini dapat diandalkan untuk penyimpanan file softcopy dikarenakan tersedia beberapa pendukung yang diberikan oleh google. Kemampuan menyimpan file pembelajaran belum dimanfaatkan banyak oleh pendidik pada saat ini. Menggunakan penyimpanan data pembelajaran membantu guru untuk tidak kehilangan file penting pembelajaran. Kemampuan penyimpanan ini perlu ditingkat oleh guru terutama untuk masa yang akan datang. Selain itu kemampuan mengetahuai teknologi secara umum perlu dimiliki oleh guru dikarenakan memberikan dampak terhadap anak didik. (Delgado, Wardlow, McKnight, \& O’Malley, 2015) kurangnya kemampuan guru memiliki hubungan yang positif terhadap kemampuan komputer peserta didik. Dukungan teknis di lingkungan sekolah terbukti memberikan pengaruh terhadap penggunaan teknologi oleh guru di kelas. Dengan menggunakan teknologi menawarkan guru untuk mengubah cara mengajar mereka dan memberikan manfaat kepada peserta didik.

\section{d. Menggunakan teknologi mengkomunikasikan bahan dan hasil pembelajaran Pengembangan 55.97\% kategori rendah}

(Trisnani, 2017) pada saat ini masyarakat sudah menggunakan perangkat teknologi untuk informasi dan komunikasi. Untuk menyampaikan informasi dan komunikasi tersebut dengan menggunakan aplikasi Facebook, instragram, gogle+, twitter, LinkedIn, YouTube, Whatsapp, dan Telegram. Selain itu penggunaan email sudah menjadi budaya dalam mengkomunikasikan pesan dalam situasi formal. Memiliki kemampuan untuk menggunakan email dan sosial media yang lain merupakan nilai tambah bagi seorang guru untuk dapat menyampaikan bahan dan hasil belajar kepada orang lain seperti orang tua anak. (L. F. Ahmad \& Jusniar, 2014) menggunakan 


\section{Febrialismanto1, Hidayatun Nur2}

email dapat memberikan pengaruh terhadap belajar. Mengkomunikasikan tugas dengan menggunakan email merupakan cara baru yang dapat dilakukan oleh guru dalam menginformasikan pembelajaran. (Juraman, 2014b) memanfaatkan andorid untuk mendapatkan informasi dan komunikasi efektif dalam pembelajaran. Hampir settiap orang sekarang menggunakan dan mengoperasikan android. Android mendapat tempat yang penting dalam kehidupan manusia. Android setiap hari digunakan untuk mendapatkan informasi dan berkomunikasi dengan orang lain. Dalam kegiatan pembelajaran seorang guru dapat memanfaatkan android untuk menyampai bahan belajar kepada anak didiknya atau menginformasikan informasi yang bersifat pendidikan kepada orang tua anak. Umpan balik yang cepat bisa didapatkan oleh guru dengan memanfaatkan media yang tersedia di dalam android. (Anwar \& Rusmana, 2017) Pesan digital sangat mudah dibuat dan disajikan, lebih membuat pembaca lebih tertarik sehingga dapat memberikan dampak dan reaksi pembaca yang lebih besar dan luas.

\section{e. Menggunakan Teknologi untuk menyebarkan informasi bahan dan hasil pembelajaran Pengembangan 55.97\% kategori rendah}

(Fitriani, 2017) media sosial merupakan adalah sarana yang sangat membantu untuk menyebarkan informasi pada saat ini. Penyebaran informasi harus memperhatikan aturan dan etika yang berlaku. (A. Ahmad, 2012) penggunaan teknologi sudah masuk dalam semua aspek kehidupan manusia. Dengan kecangihan yang dimiliki oleh teknologi membawa manusia pada sebuah tatanan yang memiliki standar hidup yang lebih baik. pembekalan pengetahuan dan etika pada orang yang menggunakan teknologi penting untuk dimiliki. (Rohmiyati, 2018) media sosial dapat digunakan untuk menyebarkan informasi sesuai pengguna pikirkan. (Mulawarman \& Nurfitri, 2017) perilaku manusia semakin hari tidak dapat dipisahkan dari dunia maya harus mendapatkan perhatian yang serius. (Widayanti, 2015) menggunakan media sosial untuk menyampaikan informasi dengan kontribusi aktif akan mendapatkan tanggapan yang baik. (Situmorang, 2012) penggunaan internet dapat digunakan oleh semua bidang pengetahuan yang berkaitan dengan manusia. Penyampaian informasi dengan media internet dapat dengan mudah disampaikan kepada masyarakat.

\section{SIMPULAN}

Secara umum dapat diketahui bahwa guru masih belum banyak menggunakan TIK untuk pembelajaran pengembangan di Taman Kanak-Kanak. Penggunaan TIK untuk pengembangan 


\section{Febrialismanto1, Hidayatun Nur2}

masih termasuk dalam kategori rendah. Penggunaan TIK tersebut berupa membuat bahan ajar, mengubah pembelajaran, menyimpan bahan dan hasil pembelajaran, mengkomunikasikan bahan dan hasil pembelajaran, serta menyebarkan informasi bahan dan hasil pembelajaran.

\section{REFERENSI}

Ahmad, A. (2012). Perkembangan Teknologi Komunikasi dan Kesenjangan Informasi. Jurnal Dakwah Tabligh, 13(1), 137-149.

Ahmad, L. F., \& Jusniar, H. M. Y. (2014). Pengarub E-Mail pada Pemberian Tugas dengan Menggunakan Pembelajaran Langsung terhadap Hasil Belajar Siswa Kelas XI IPA SMA Negeri 1 Bajeng (Studi pada Sub. Materi Pokok Hidrolisis Garam) The Influenced of Email to Present Task with Direct Learning to. 15(2), 1-15.

Ahmadi, D. M. R. (2018). The Use of Technology in English Language Learning: A Literature Review. International Journal of Research in English Education, 3(2), 115-125. https://doi.org/10.29252/ijree.3.2.115

Anwar, R. K., \& Rusmana, A. (2017). KOMUNIKASI DIGITAL BERBENTUK MEDIA SOSIAL DALAM MENINGKATKAN KOMPETENSI BAGI KEPALA, PUSTAKAWAN, DAN TENAGA PENGELOLA PERPUSTAKAAN (Studi Kasus pada Sekolah/Madrasah di Desa Kayu Ambon, Kecamatan Lembang Kabupaten Bandung Barat). Jurnal Aplikasi Ipteks Untuk. Masyarakat, 6(3), 204-208. Retrieved from journdharmakarya/article/viewFile/11437/5233al.unpad.ac.id/

Arsanti, M. (2018). Pengembangan Bahan Ajar Mata Kuliah Penulisan Kreatif Bermuatan NilaiNilai Pendidikan Karakter Religius Bagi Mahasiswa Prodi Pbsi, Fkip, Unissula. KREDO : Jurnal Ilmiah Bahasa Dan Sastra, 1(2), 71-90. https://doi.org/10.24176/kredo.v1i2.2107

Budiman, H. (2017). Peran Teknologi Informasi Dan Komunikasi Dalam Pendidikan. AlTad₹kiyyah: Jurnal Pendidikan Islam, 8(1), 31. https://doi.org/10.24042/atjpi.v8i1.2095

Cahyono, G. H. (2012). Mengenal \& Menggunakan Google Drive. Forum Teknologi, 03(1), 43-48. Retrieved from http://www.cloudindonesia.or.id/mengenal-menggunakan-googledrive.html

Chaidar, H. (2014). Pemanfaatan Teknologi Informasi dan Komunikasi dalam Pembelajaran. Jurnal Pendidikan Penabur, 2(2), 184-192. Retrieved from http://physicsmaster.orgfree.com/Artikel \%26 Jurnal/Inovasi Dalam Pendidikan/Teknologi Komunikasi.pdf 


\section{Febrialismanto1, Hidayatun Nur2}

Delgado, A. J., Wardlow, L., McKnight, K., \& O’Malley, K. (2015). Educational technology: A review of the integration, resources, and effectiveness of technology in K-12 classrooms. Journal of Information Technology Education: Research, 14(2015), 397-416. https://doi.org/10.28945/2298

Febrialismanto, \& Hukmi. (2018). Perbedaan Kompetensi Profesional Guru PG PAUD Kabupaten Siak Dengan Kabupaten Kampar Provinsi Riau. 7(1), 61-68. Retrieved from https://ejournal.unri.ac.id/index.php/JPSBE/article/view/5114/4793

Fitriani, Y. (2017). Analisis Pemanfaatan Berbagai Media Sosial Sebagai Sarana Penyebaran Informasi Bagi Masyarakat. 19(2), 148-152. Retrieved from Media Sosial, Penyebaran Informasi, UU ITE

Indonesia, P. M. P. dan K. R. (2014). Kurikulum 2013 Pendidikan Anak Usia Dini.

Juraman, S. R. (2014a). Pemanfaatan Information and Communication Technology bagi Pengembangan Guru Madrasah Sub Urban. Dimas: Jurnal Pemikiran Agama Untuk Pemberdayaan, 16(2), 309. https://doi.org/10.21580/dms.2016.162.1095

Juraman, S. R. (2014b). PEMANFAATAN SMARTPHONE ANDROID OLEH MAHASISWA ILMU KOMUNIKASI DALAM MENGAKSES INFORMASI EDUKATIF. ACTA DIURNA KOMUNIKASIACTA DIURNA KOMUNIKASI, 3(1).

Mulawarman, \& Nurfitri, A. D. (2017). Perilaku Pengguna Media Sosial beserta Implikasinya Ditinjau dari Perspektif Psikologi Sosial Terapan. 25(1), 36-44. https://doi.org/10.22146/buletinpsikologi.22759

Mutia, I. (2016). Pemanfaatan Komputasi Awan (Cloud Computing) Bagi Pembelajaran Mahasiswa Perguruan Tinggi. STRING (Satuan Tulisan Riset Dan Inovasi Teknologi), 1(1), 1-9. https://doi.org/10.30998/string.v1i1.963

Rahman, U. (2009). Karakteristik Perkembangan Anak Usia Dini. Lentera Pendidikan : Jurnal Ilmu Tarbiyah Dan Keguruan, 12(1), 46-57. https://doi.org/10.24252/lp.2009v12n1a4

Rifauddin, M. (2016). Pengelolaan Arsip Elektronik Berbasis Teknologi. Khizanah Al- Hikmah: Jurnal Ilmu Perpustakaan, Informasi, Dan Kearsipan, 4(2), 168-178.

Rohmiyati, Y. (2018). Analisis Penyebaran Informasi Pada Sosial Media. Anwva, 2(1), 29. https://doi.org/10.14710/anuva.2.1.29-42

Romansyah, K. (2016). Pedoman Pemilihan dan Penyajian Bahan Ajar Mata Pelajaran Bahasa dan Sastra Indonesia. Jurnal Logika, XVII(2), 59-66. Retrieved from http://jurnal.unswagati.ac.id/index.php/logika/article/download/145/97 


\section{Febrialismanto1, Hidayatun Nur2}

Rusi Restiyani, Nengsi Juanengsih, Y. H. (2013). Profil Pemanfaattan Teknologi Informasi dan Komunikasi (TIK) Sebagai Media dan Sumber Pembelajaran Oleh Guru Biologi. Journal of Chemical Information and Modeling, 53(9), 1689-1699. https://doi.org/10.1017/CBO9781107415324.004

Saida Ulfa. (2016). Pemanfaatan teknologi bergerak sebagai media pembelajaran bagi anak usia dini. Edcomtech, 1(1), 1-8.

Setyosari, P. (2015). Tantangan Dan Peran Teknologi Pembelajaran Transformasi Pendidikan Di Era Digital. Seminar Nasional Teknologi Pendidikan UM, 2015, 484-496.

Situmorang, J. (2012). Pemanfaatan Internet Sebagai New Media Dalam Bidang Politik, Bisnis, Pendidikan Dan Sosial Budaya. Jurnal Administrasi Bisnis, 8(1), 77-91.

Trisnani. (2017). PEMANFAATAN WHATS APP SEBAGAI MEDIA KOMUNIKASI DAN Whats App Utilization As Media Communication and Satisfaction In Submission of Messages among People of the Community. 6(3), 1-12.

Widayanti, R. (2015). Pemanfaatan Media Sosial Untuk Penyebaran Informasi. Abdimas, 1(2), 8187. Retrieved from https://www.esaunggul.ac.id/wpcontent/uploads/2018/08/Pemanfataan-Media-Sosial-untuk-Penyebaran-InformasiKegiatan-Sekolah-Menengah-Kejuruan-Pasundan-Tangerang.pdf

Wirastuti, N. M. A. E. D., Hartawan, I. G. A. K. D. D., Suyadnya, I. M. A., \& Khrisne, D. C. (2018). Pengembangan Media Pembelajaran Teknologi Informasi Dan Komunikasi Berbasis Multimedia Bagi Guru-Guru Sekolah Dasar Di Desa Kintamani Bangli. Buletin Udayana Mengabdi, 17(1), 134. https://doi.org/10.24843/bum.2018.v17.i01.p23

Yaumi, M. (2016). TERMINOLOGI TEKNOLOGI PEMBELAJARAN: Suatu Tinjauan Historis. $V(1), 191-208$.

Zakiah, M., Suyono, \& Roekhan. (2012). PENGEMBANGAN BAHAN AJAR PENDIDIKAN BERPIKIR KRITIS MELALUI PEMBELAJARAN MENULIS KARYA ILMIAH DI SMA/MA KELAS XI. JOM Bahasa Dan Seni UM, 1(1), 1-9. Retrieved from http://jurnalonline.um.ac.id/data/artikel/artikel7FCEEE9CC1FAF56E9B661B2F44619E45.pdf

Zuriah, N., Sunaryo, H., \& Yusuf, N. (2016). IbM GURU DALAM PENGEMBANGAN BAHAN AJAR KREATIF INOVATIF BERBASIS POTENSI LOKAL Nurul Zuriah 1 , Hari Sunaryo 2 , Nurbani Yusuf 3. Dedikasi, 13, 40. Retrieved from 1693-3214 